\title{
Breast Burkitt Lymphoma
}

National Cancer Institute

\section{Source}

National Cancer Institute. Breast Burkitt Lymphoma. NCI Thesaurus. Code C40376.

A Burkitt lymphoma that arises from the breast. It usually affects pregnant or lactating women and presents with bilateral breast involvement and breast swelling. 